\title{
Psychiatry
}

\section{Combined Antirelapse Therapy in Patients with Schizoaffective Disorder: A Prospective Cohort Study}

\author{
Michael A. Nekrasov, $\mathrm{PhD}, \mathrm{ScD}^{1}$; Dmitriy F. Khritinin, $\mathrm{PhD}, \mathrm{ScD}^{2}$; \\ Maria A. Sumarokova, $\mathrm{PhD}^{2}$; Zhanna R. Gardanova, $\mathrm{PhD}, \mathrm{ScD}^{3}$; \\ Alexander V. Esin'2; Elena P. Shchukina, $\mathrm{PhD}^{2}$ \\ ${ }^{1}$ Medicine Institute, I.S. Turgenev Oryol State University, Orel \\ ${ }^{2}$ I.M. Sechenov First Moscow State Medical University, Moscow \\ ${ }^{3}$ Pirogov Russian National Research Medical University, Moscow \\ The Russian Federation
}

\begin{abstract}
Background: In most studies, patients with schizoaffective disorder (SAD) are often combined into one group along with schizophrenia patients or less commonly with those suffering from affective disorders, which makes it difficult to obtain data about the peculiarities of SAD treatment. Articles dedicated to SAD treatment in the interictal period are rare.

Methods and Results: The prospective cohort study was conducted from 2011 to 2015. The study involved 86 patients diagnosed with SAD according to ICD-10. Patients received neuroleptics (NLs) as antirelapse therapy for 2 years (NL therapy); then mood stabilizers (MSs) were added to the antirelapse treatment (NL+MS therapy). The results of this combined therapy with MSs were evaluated after 2 years of treatment. Our results suggest that the use of combination therapy that includes antipsychotics and MSs leads to maintenance of a higher quality remission. Remission becomes more prolonged and affective swings less pronounced, resulting in improved quality of life in SAD patients. Improving the quality of remission can be attributed to the following characteristics of the combined therapy: a) the use of lower doses of neuroleptics; b) a reduction in the frequency and severity of mood swings; and c) an increase in patient compliance.

Conclusion: The use of combined pharmacotherapy including antipsychotics and MSs produces a longer, high-quality remission. The inclusion of MSs in the scheme of treatment increases the patient adherence to a medication regimen. The use of MSs in combination therapy reduces affective fluctuations, thereby increasing the probability of maintaining remission with complete symptom relief. (Int J Biomed. 2016;6(2):119-123.).
\end{abstract}

Key Words: schizoaffective disorder • antirelapse therapy $\bullet$ mood stabilizers $\bullet$ high-quality remission

\section{Introduction}

According to various studies, the prevalence of schizoaffective disorder (SAD) ranges from about $0.2 \%$ to $1.1 \%$ of the population worldwide. ${ }^{[1]}$ This diversity in estimates of the prevalence is due to variations in the diagnostic criteria used by the authors; however, most agree on the criteria of ICD-10 and DSM-5. ${ }^{[2,3]}$ Until now, researchers have not decided on the independence of this disorder, and SAD is often included in the spectrum of schizophrenic disorders;

Corresponding author: Prof. Michael A. Nekrasov, PhD, ScD. Department of psychiatry and neurology, Medicine Institute, I.S. Turgenev Oryol State University. Oryol, Russia; E-mail: nekrasovma77@yandex.ru rarely, it is referred to as bipolar disorder. ${ }^{[3-7]}$ According to some studies, an overlap between schizophrenia, SAD and bipolar affective disorder type I was observed at the evaluation of genetic and biological parameters. ${ }^{[1,8,9]}$ However, there are a number of modern clinical, molecular-genetic, biochemical and histological studies confirming the validity of segregation of such a nosological unit as schizoaffective disorder. ${ }^{[1,3,10-13]}$ Researchers distinguish several SAD features, such as greater frequency of hospitalizations of SAD patients in comparison with patients suffering from schizophrenia and, at the same time, a high potential for recovery and social adaptation of patients with SAD. ${ }^{[13,14]}$

Currently, the main objective of mental health care is not only the elimination of mental illness symptoms, but also the restoration of the original level of social functioning and 
quality of life, if possible. In this regard, particular attention is paid to the maintenance of high-quality remission.

Remission quality is defined by its duration, the presence or absence of residual symptoms, and the level of social adaptation. Preventive treatment can improve the quality of SAD remission. ${ }^{[13]}$ There is an ongoing dispute about necessity and duration of maintenance therapy in SAD. The most commonly administered treatment includes antidepressants and antipsychotics. ${ }^{[1,14,15]}$ Possibilities of preventive treatment expanded considerably after the introduction of mood stabilizers (MSs). ${ }^{[1,3,19]}$ The preference is currently given to atypical antipsychotic medications which have a mood stabilizing effect in addition to an antipsychotic one. ${ }^{[16,17,20]}$ The most frequently prescribed are second-generation antipsychotics, but the high cost and side effects (weight gain and sexual dysfunction) lead to patients with SAD abandoning treatment. ${ }^{[16-18]}$ The combination of antipsychotics and MSs may be effective and more easily tolerated by patients, reducing the overall neuroleptic load as a result. Articles dedicated to SAD treatment in the interictal period are rare. ${ }^{[9,20]}$

In most studies, SAD patients are often combined into one group along with schizophrenia patients or less commonly with those suffering from affective disorders, ${ }^{[18-20]}$ which makes it difficult to obtain data about the peculiarities of $\mathrm{SAD}$ treatment. Therefore, it became necessary to investigate the influence of different types of therapy on the quality of remission in schizoaffective disorder.

\section{Materials and Methods}

The prospective cohort study was conducted from 2011 to 2015. Patients were observed in S.S. Korsakov Clinic of Psychiatry of I.M. Sechenov First Moscow State Medical University (MSMU) and in the Moscow outpatient psychiatric clinic No7.

Patient selection was carried out after the approval by the ethics committee of I.M. Sechenov First MSMU. After complete description of the study, written informed consent was obtained from all patients.

The study involved 86 patients $(50 / 58.13 \%$ men and $36 / 41.87 \%$ women) diagnosed with SAD according to ICD10. The duration of the disease ranged from 4 to 32 years. The average age of patients was $31.17 \pm 6.2$ years at the start of the survey and $25.53 \pm 7.93$ years at diagnosis of the disease.

Exclusion criteria were presence of significant physical disorders, exogenous organic disorders and substance dependence.

The first survey was carried out during one week after patients were discharged from a psychiatric hospital. To study the characteristics of SAD remission, clinicalpsychopathological and clinical follow-up survey with a structured interview were conducted. The hospital discharge reports were also examined. Later, patients visited the clinic every month, and if they did not come, a nurse communicated with them in order to find out the reason for the absence. In case of an exacerbation, patients were re-admitted to the hospital and were observed again after discharge.

In the study, patients received neuroleptics (NLs) as antirelapse therapy for 2 years (NL therapy); then MSs were added to the antirelapse treatment (NL+MS therapy). The results of this combined therapy with MSs were evaluated after 2 years of treatment. Patients with $\mathrm{NL}+\mathrm{MS}$ therapy were also divided into 3 subgroups according to the MS incorporated in the therapy (LC - lithium carbonate, CBM - carbamazepine, VA - valproic acid).

Patients were surveyed by clinical and psychopathological methods and a structured interview; we also conducted interviews with patients' relatives and studied patients' medical records.

By the beginning of this study, the remission in patients was either with complete reduction of psychopathology or we detected anxiety, depressed mood, and residual delusions.

Patients were treated with typical neuroleptics from butyrophenone (haloperidol), piperazine phenothiazines (trifluperazin) groups, atypical antipsychotics group of benzodiazepines (clozapine, olanzapine), benzisoxazole derivatives (risperidone).

Tricyclic (amitriptyline, clomipramine) and heterocyclic (mirtazapine) antidepressants, selective serotonin reuptake inhibitors (paroxetine, fluvoxamine), and antiparkinsonian drugs (trihexyphenidyl) were prescribed if necessary.

More details on drugs used are given in Tables 1 and 2.

Statistical analysis was performed using the SPSS for Windows. Baseline characteristics were summarized as frequencies and percentages for categorical variables and as mean (M) and standard error of the mean (SEM) for continuous variables. Student's unpaired and paired t-tests were used to compare two groups for data with normal distribution. Comparisons between three groups were performed with the one-way ANOVA with Tukey's post-hoc test. Group comparisons with respect to categorical variables are performed using chi-square test. A probability value of $P<0.05$ was considered statistically significant.

Table 1.

Doses (mg) of antipsychotics used for SAD patient treatment

\begin{tabular}{|l|c|c|c|c|}
\hline \multirow{2}{*}{ Medication } & \multicolumn{2}{|c|}{ NL therapy $(\mathrm{n}=86)$} & \multicolumn{2}{c|}{ NL+MS therapy $(\mathrm{n}=86)$} \\
\cline { 2 - 5 } & $\mathrm{M} \pm$ SEM & Mode & $\mathrm{M} \pm$ SEM & Mode \\
\hline Haloperidol & $9.68 \pm 1.22$ & 15 & $5.14 \pm 2.32$ & 4.5 \\
\hline Trifluperazin & $23.01 \pm 3.35$ & 25 & $27.43 \pm 9.47$ & 25 \\
\hline Clozapine & $197.46 \pm 33.53$ & 200 & $108.79 \pm 9.97$ & 100 \\
\hline Olanzapine & $18.86 \pm 1.98$ & 20 & $5.98 \pm 2.76$ & 5 \\
\hline Risperidone & $4.13 \pm 0.22$ & 4 & $3.33 \pm 0.57$ & 2 \\
\hline
\end{tabular}

Table 2.

Mood stabilizers (mg) used for antirelapse therapy for SAD patients (Group NL+MS)

\begin{tabular}{|l|c|c|c|c|c|c|}
\hline Medication & Mean & Mode & $\begin{array}{c}\text { Minimum } \\
\text { value }\end{array}$ & $\begin{array}{c}\text { Maximum } \\
\text { value }\end{array}$ & $\begin{array}{c}\text { Standard } \\
\text { Deviation }\end{array}$ & $\begin{array}{c}\text { Number } \\
\text { of patients }\end{array}$ \\
\hline LC & 743.75 & 900 & 500.000 & 900.000 & 151.20 & $40 / 46.5$ \\
\hline CBM & 376.92 & 300 & 100.000 & $1,200.00$ & 341.94 & $17 / 19.8$ \\
\hline VA & 622.72 & 600 & 100.000 & $1,200.00$ & 385.98 & $29 / 33.7$ \\
\hline
\end{tabular}




\section{Results}

Treatment with only NLs was associated with a shorter remission (less than 1 year) compared to treatment with NLs plus MSs. Adding MSs to the therapy significantly increased the mean duration of remission (Table 3).

In order to study alterations in the ratio of hospitalization length to the duration of remission under the influence of various types of antirelapse therapy, we used the efficiency ratio (ER), the integral indicator reflecting the overall antirelapse effect of different medical regimens. The lower the score, the longer the remission and the shorter the subsequent hospitalization (ie, the medical regimen has a more pronounced preventive effect.) In NL therapy, ER was 0.34 . In NL+MS therapy, ER was significantly lower compared to all other types of NL therapy. In patients receiving a medical regimen that comprised lithium carbonate, the efficiency ratio was 0.21 . ER in patients who received carbamazepine and valproic acid was 0.26 and 0.17 , respectively. Consequently, valproic acid has the best preventive effect; however, such results may be related to features of the patient sample. At the same time, according to recent data, valproate has a preventive effect not just against maniacal, but also against depressive episodes, which may explain their advantage over the other drugs.

In the study of the impact of MS antirelapse therapy on the risk of exacerbations in 6,12 and 24 months of treatment, the following results were obtained: In the first 6 months of preventive treatment, the use of MSs reduced the risk of exacerbations by 1.7 times; in patients taking MS treatment for 12 months and others for 2 years, this risk was 1.6 and 1.7 times less than that of patients treated with only NLs.
Thus, during the first 2 years of MS preventive treatment, the risk of disease exacerbation remained constant and was lower than in patients not receiving such therapy. During the first 3 years following the SAD attack, the risk of exacerbation in patients treated with NLs+MSs was 1.6 times less than that of patients treated with only NLs (Table 3 ).

During NL+MS therapy, the proportion of patients without residual symptoms increased twofold, mainly due to the reduction in the number of patients with affective symptoms (Table 4).

It was also found that MSs have a pronounced antisuicidal effect: absolute risk to commit suicidal acts in patients taking MSs was 0.042 ; in those who did not receive these drugs -0.235 . The odds ratio for patients receiving and not receiving mood stabilizers was $0.014(P=0.02)$.

Furthermore, the application of MSs resulted in an increase in the SAD patient compliance. This was due to a decrease in the severity of mood swings and a reduction of irritability and neuroleptic total load in chlorpromazine equivalents. High neuroleptic load is known to cause side effects that often lead to abandonment of treatment, irregularity in reception of drugs, and a search for specialists in alternative medicine. It turned out that supplementation of MSs can reduce the neuroleptic load about 1.5 to 2 times (Table 5).

Patients treated with NL+MS were rarely treated with antiparkinsonians or tranquilizers (Table 6).

When analyzing the structure of exacerbations in examined patients after different types of preventive treatment, we found that the application of MSs in combination with other drugs clearly reduced the proportion of episodes with manic affect (Table 7).

Table 3.

The duration of remission and the average length of hospital stay for different types of therapy

\begin{tabular}{|c|c|c|c|c|c|c|c|c|c|c|c|}
\hline & \multirow{2}{*}{$\begin{array}{c}\text { NL/LC+ } \\
(n=40)\end{array}$} & \multirow{2}{*}{$P$} & \multirow{2}{*}{$\begin{array}{c}\text { NL/LC- } \\
(\mathrm{n}=40)\end{array}$} & \multirow{2}{*}{$\begin{array}{c}\text { NL/CBM+ } \\
(n=17)\end{array}$} & \multirow{2}{*}{$P$} & \multirow{2}{*}{$\begin{array}{c}\text { NL/CBM- } \\
(n=17)\end{array}$} & \multirow{2}{*}{$\begin{array}{c}\text { NL/VA+ } \\
(n=29)\end{array}$} & \multirow{2}{*}{$P$} & \multirow{2}{*}{$\begin{array}{l}\text { NL/VA- } \\
(n=29)\end{array}$} & \multicolumn{2}{|c|}{ ANOVA } \\
\hline & & & & & & & & & & $\mathrm{NL} / \mathrm{MS}+$ & NL/MS- \\
\hline $\begin{array}{l}\text { Duration of } \\
\text { remission } \\
\text { (days) }\end{array}$ & $338.9 \pm 22.1$ & 0.0038 & $231.48 \pm 15.9$ & $440.9 \pm 38.7$ & 0.0049 & $233.6 \pm 42.9$ & $522.2 \pm 101.1$ & 0.0045 & $212.2 \pm 36$ & $\begin{array}{l}F=2.5129 \\
P=0.0872\end{array}$ & $\begin{array}{l}F=0.1587 \\
P=0.8535\end{array}$ \\
\hline $\begin{array}{l}\text { Length of } \\
\text { hospital stay } \\
\text { (days) }\end{array}$ & $66.1 \pm 6.9$ & 0.2190 & $73.2 \pm 9.3$ & $69.0 \pm 10.7$ & 0.5831 & $68.5 \pm 12.8$ & $84.5 \pm 13.4$ & 0.6513 & $72.78 \pm 19.9$ & $\begin{array}{l}F=0.9929 \\
P=0.3749\end{array}$ & $\begin{array}{l}F=0.0231 \\
P=0.9772\end{array}$ \\
\hline
\end{tabular}

Table 4.

Residual symptoms after remission on the background of various types of antirelapse therapy

\begin{tabular}{|c|c|c|c|c|c|c|c|}
\hline Variable & $\begin{array}{c}\mathrm{NL} \\
(\mathrm{n}=86)\end{array}$ & $P$ & $\begin{array}{c}\text { NL+MS } \\
(n=86)\end{array}$ & $\begin{array}{c}\mathrm{NL}+\mathrm{LC} \\
(\mathrm{n}=40)\end{array}$ & $\begin{array}{c}\mathrm{NL}+\mathrm{CBM} \\
(\mathrm{n}=17)\end{array}$ & $\begin{array}{c}\mathrm{NL}+\mathrm{VA} \\
(\mathrm{n}=29)\end{array}$ & $P$ \\
\hline Subdepression & $40 /(46.5 \%)$ & $>0.05$ & $46 /(53.5 \%)$ & $30 /(75.0 \%)$ & $5 /(29.4 \%)$ & $11 /(37.9 \%)$ & 0.0008 \\
\hline
\end{tabular}


Table 5.

Total neuroleptic load in chlorpromazine equivalent (CPZE) on the background of various types of antirelapse therapy

\begin{tabular}{|c|c|c|c|c|c|c|c|c|c|c|}
\hline Variable & $\begin{array}{c}\mathrm{NL} / \mathrm{LC}+ \\
(\mathrm{n}=40)\end{array}$ & $P$ & $\begin{array}{c}\text { NL/LC- } \\
(\mathrm{n}=40)\end{array}$ & $\begin{array}{c}\text { NL/CBM+ } \\
(\mathrm{n}=17)\end{array}$ & $P$ & $\begin{array}{c}\text { NL/CBM- } \\
(\mathrm{n}=17)\end{array}$ & $\begin{array}{c}\text { NL/VA+ } \\
(\mathrm{n}=29)\end{array}$ & $P$ & $\begin{array}{c}\text { NL/VA- } \\
(\mathrm{n}=29)\end{array}$ & \multicolumn{2}{|c|}{ ANOVA } \\
\hline CPZE, mg & $170.00 \pm 35.9$ & 0.001 & $336.7 \pm 29.1$ & $218.12 \pm 56.8$ & 0.004 & $348.56 \pm 46.9$ & $226.22 \pm 63.7$ & 0.004 & $316.8 \pm 56.2$ & $\begin{array}{l}\text { NL/MS- } \\
P=0.4110\end{array}$ \\
\hline$P=0.6643$ & $F=0.1117$ \\
$P=0.8891$ \\
\hline
\end{tabular}

Table 6.

Treatment with antiparkinsonians and tranquilizers on the background of different types of therapy

\begin{tabular}{|c|c|c|c|c|c|c|}
\hline \multirow{2}{*}{ Group } & \multicolumn{3}{|c|}{ Antiparkinsonian drugs } & \multicolumn{3}{c|}{ Tranquilizer drugs } \\
\cline { 2 - 7 } & No & $P$ & Yes & No & $P$ & Yes \\
\hline NL therapy & $35 /(40.7 \%)$ & 0.01 & $51 /(59.3 \%)$ & $66 /(76.7 \%)$ & 0.000 & $20 /(23.2 \%)$ \\
\hline NL+MS therapy & $61 /(70.9 \%)$ & 0.000 & $25 /(29.1 \%)$ & $79 /(91.9 \%)$ & 0.000 & $7 /(8.1 \%)$ \\
\hline$P$ & 0.000 & & 0.000 & 0.006 & 0.006 \\
\hline
\end{tabular}

Table 7.

The structure of exacerbations in examined patients after different types of preventive treatment

\begin{tabular}{|l|c|c|c|c|c|c|c|}
\hline \multicolumn{1}{|c|}{ Episode type } & $\begin{array}{c}\mathrm{NL} \\
\mathrm{n}=86\end{array}$ & $P$ & $\begin{array}{c}\mathrm{NL}+\mathrm{MS} \\
\mathrm{n}=86\end{array}$ & $\begin{array}{c}\mathrm{NL}+\mathrm{LC} \\
\mathrm{n}=40\end{array}$ & $\begin{array}{c}\mathrm{NL}+\mathrm{CBM} \\
\mathrm{n}=17\end{array}$ & $\begin{array}{c}\mathrm{NL}+\mathrm{VA} \\
\mathrm{n}=29\end{array}$ \\
\hline Depressive & $18 /(20.9 \%)$ & 0.0000 & $66 /(76.7 \%)$ & $34 /(85.0 \%)$ & $6 /(35.3 \%)$ & $26 /(89.6 \%)$ & 0.0000 \\
\hline Manic & $68 /(79.1 \%)$ & 0.0000 & $20 /(23.2 \%)$ & $6 /(15.0 \%)$ & $11 /(64.7 \%)$ & $3 /(10.3 \%)$ & 0.0000 \\
\hline
\end{tabular}

According to our data, patients receiving MSs in their therapy scheme were 5 times more likely to adhere to their medical regimen (Table 8). Thus, we can conclude that the inclusion of MSs in the scheme of treatment increases the patient adherence to a medication regimen.

Table 8.

Adherence to medical regimen in different types of antirelapse treatment

\begin{tabular}{|l|c|c|c|}
\hline \multicolumn{1}{|c|}{ Variable } & $\begin{array}{c}\text { NL } \\
(\mathrm{n}=86)\end{array}$ & $P$ & $\begin{array}{c}\mathrm{NL}+\mathrm{MS} \\
(\mathrm{n}=86)\end{array}$ \\
\hline $\begin{array}{l}\text { Refusal of medication or } \\
\text { irregular use of medication }\end{array}$ & $64 /(74.4 \%)$ & 0.0000 & $30 /(34.9 \%)$ \\
\hline Regular use of medication & $22 /(25.6 \%)$ & 0.0000 & $56 /(65.1 \%)$ \\
\hline
\end{tabular}

\section{Discussion}

Our results suggest that the use of combination therapy that includes antipsychotics and MSs leads to maintenance of a higher quality remission. Remission becomes more prolonged and affective swings less pronounced, resulting in improved quality of life in SAD patients and achieving the best results in the restoration of the previous level of social functioning. Improving the quality of remission can be attributed to the following characteristics of the combined therapy: a) the use of lower doses of neuroleptics; b) a reduction in the frequency and severity of mood swings; and c) an increase in patient compliance.

The marked increase in adherence to recommendations in SAD patients using a combination therapy was determined by several factors: a) the thymostabilizing effect, which leads to a more adequate patient assessment of their own condition; b) reduction in total neuroleptic load, thereby a reduction in the number and severity of side effects, as well as an opportunity to reduce the frequency of taking the drugs to the morning and evening in order to avoid taking them during working hours (this may explain why some authors have noted a decrease in irritability of patients after MS appointment). MSs have shown high efficacy in the prevention of relapses in SAD patients, reducing the likelihood of an exacerbation by 1.7 times depending on the duration of therapy, according to our data. It is also important to note that the MS appointment has a strong antisuicidal effect, reducing this risk by 5.6 times. This is important because the probability of committing suicide during remission is highest and therefore the prevention activities in this period gain practical value.

\section{Conclusion}

In sum, we can conclude: 1) the use of combined pharmacotherapy including antipsychotics and MSs produces a longer, high-quality remission; 2) there are no statistically 
significant differences in the impact of different groups of MSs on the average duration of remission; 3 ) the inclusion of MSs in the scheme of preventive treatment has no effect on the average length of subsequent hospitalization; 4) the use of MSs in combination therapy reduces affective fluctuations, thereby increasing the probability of maintaining remission with complete symptom relief; 5) MSs are effective in the prevention of suicidal behavior; 6) the use of MSs can reduce the necessity for tranquilizers and antiparkinsonians; 7) the inclusion of MSs in the scheme of treatment increases the patient adherence to a medication regimen.

\section{References}

1. Padhy S, Hedge A. Schizoaffective Disorder: Evolution and Current Status of the Concept. Turk Psikiyatri Derg. 2015:26(2):131-7. [Article in Turkish]

2. Pagel T, Franklin J, Baethge C. Schizoaffective disorder diagnosed according to different diagnostic criteria-systematic literature search and meta-analysis of key clinical characteristics and heterogeneity. J Affect Disord. 2014;156:111-8.

3. Cosgrove VE, Suppes T. Informing DSM-5: biological boundaries between bipolar I disorder, schizoaffective disorder, and schizophrenia. BMC Med 2013;11:127.

4. Arnold SJ, Ivleva EI, Gopal TA, Reddy AP, JeonSlaughter H, Sacco CB, et al. Hippocampal volume is reduced in schizophrenia and schizoaffective disorder but not in psychotic bipolar I disorder demonstrated by both manual tracing and automated parcellation (FreeSurfer). Schizophr Bull. 2015;41(1): 233-49.

5. Amann BL, Canales-Rodríguez EJ, Madre M, Radua J, Monte G, Alonso-Lana S, et al. Brain structural changes in schizoaffective disorder compared to schizophrenia and bipolar disorder. Acta Psychiatr Scand. 2016; 133(1): 23-33.

6. Pagel T, Baldessarini RJ, Franklin J, Baethge C. Characteristics of patients diagnosed with schizoaffective disorder compared with schizophrenia and bipolar disorder. Bipolar Disord. 2013;15(3): 229-39.

7. Pagel T, Baldessarini RJ, Franklin J, Baethge C. Heterogeneity of schizoaffective disorder compared with schizophrenia and bipolar disorder. Acta Psychiatr Scand. 2013;128(4): 238-50.

8. Mancuso SG, Morgan VA, Mitchell PB, Berk M, Young A, Castle DJ A comparison of schizophrenia, schizoaffective disorder, and bipolar disorder: Results from the Second Australian national psychosis survey. J Affect Disord. 2015; 172:30-7.

9. Alastair GC, Michael JO. Genetic Relationships Between
Schizophrenia, Bipolar Disorder, and Schizoaffective Disorder. Schizophr Bull. 2014; 40(3):504-15.

10. Glausier JR, Kimoto S, Fish KN, Lewis DA. Lower glutamic acid decarboxylase $65-\mathrm{kDa}$ isoform messenger RNA and protein levels in the prefrontal cortex in schizoaffective disorder but not schizophrenia. Biol Psychiatry. 2015;77(2):167-76.

11. Martín-Subero M, Berk L, Dodd S, Kamalesh V, Maes M, Kulkarni J, et al. Quality of life in bipolar and schizoaffective disorder-a naturalistic approach. Compr Psychiatry. 2014; 55(7):1540-5.

12. Murru A, Hidalgo D, Bernardo M, Bobes J, Saiz-Ruiz J, Álamo C, Vieta E. Antipsychotic switching in schizoaffective disorder: A systematic review. World J Biol Psychiatry 2015; 9: 1-19.

13. Pinna F, Deriu L, Lepori T, Maccioni R, Milia P, Sarritzu E, et al. Is it true remission? A study of remitted patients affected by schizophrenia and schizoaffective disorders. Psychiatry Res. 2013;210(3):739-44.

14. Murru A, Pacchiarotti I, Amann BL, Nivoli AM, Vieta E, Colom F. Treatment adherence in bipolar I and schizoaffective disorder, bipolar type. J Affect Disord. 2013;151(3):1003-8.

15. McDonnell DP, Landry J, Detke HC. Long-term safety and efficacy of olanzapine long-acting injection in patients with schizophrenia or schizoaffective disorder: a 6-year, multinational, single-arm, open-label study. Int Clin Psychopharmacol. 2014; 29(6):322-31

16. Baethge C. Long-term treatment of schizoaffective disorder: review and recommendations. Pharmacopsychiatry. 2003; 36(2):45-56.

17. Nimura S, Yamaguchi T, Ueda K, Kadokura K, Aiuchi $\mathrm{T}$, Kato $\mathrm{R}$, et al. Olanzapine promotes the accumulation of lipid droplets and the expression of multiple perilipins in human adipocytes. Biochem Biophys Res Commun. 2015;467(4):906-12.

18. Pandey GN, Pandey SC, Ren X, Dwivedi Y, Janicak PG. Serotonin receptors in platelets of bipolar and schizoaffective patients: effect of lithium treatment. Psychopharmacology (Berl) 2003;170(2):115-23.

19. Fu DJ, Turkoz I, Simonson RB, Walling DP, Schooler NR, Lindenmayer JP, et al. Paliperidone palmitate oncemonthly reduces risk of relapse of psychotic, depressive, and manic symptoms and maintains functioning in a doubleblind, randomized study of schizoaffective disorder. J Clin Psychiatry. 2015;76(3):253-62.

20. Masand PS, Wang X, Gupta S, Schwartz TL, Virk S, Hameed A. Comparison of Risperidone and Olanzapine in Bipolar and Schizoaffective Disorders. Prim Care Companion J Clin Psychiatry. 2002; 4(2):70-73. 